The last chapter draws the conclusion. It sums up the book's main ideas, and emphasises the key theoretical background and advice on how to use picturebooks to promote critical thinking. It highlights the importance of reading and thinking about one's reading, in light of its importance in life in general. A useful appendix follows, providing a list of recommended picturebooks arranged by topic. Those new to teaching or to picturebooks will find this particularly appealing.

In sum, the effect of the book is that the reader feels inspired and ready to get down to the business of developing children's critical thinking through picturebooks. Roche's lucid writing style makes the subject easy to understand, and the numerous examples and advice encourage the reader to take on board the concepts that are expounded in this engaging and accessible book.

Željka Gosarić

\title{
Getting It Right from the Start
}

Janice Bland, ed. 2015. Teaching English to Young Learners: Critical Issues in Language Teaching with 3-12 Year Olds. London: Bloomsbury. 293 pp. ISBN 978$1-4725-8856-2$

DOI: $10.21066 /$ carcl.libri.2017-06(01).0008

The gradual establishment of English as a global lingua franca of sorts has (among other things) led not only to the inclusion of English language (EL) classes into school curricula, but in recent years also to the slow but steady lowering of the age at which foreign language instruction is first introduced to students. The attitude that (when it comes to foreign language learning) younger is necessarily better has, for the most part, been uncritically accepted, resulting in a worldwide trend of early primary, and especially preprimary language learning programmes. While the term "young learner" (YL) has therefore been significantly expanded, its newest component, pre-primary learners (age 3-6), is not always recognised as a separate group with its own specific needs and learning style. As such, it is still largely overlooked in both theory (a dearth of research on the subject), and practice. Teachers of English for young learners (EYL) often receive little to no special training to meet the specific needs of (pre-)primary learners (who, having "no immediate need to use English and therefore no need to learn it", are highly dependent on teachers; 279) and they lack appropriate resources, and even motivation.

Aimed at addressing some of the problematic points outlined above, the edited volume Teaching English to Young Learners: Critical Issues in Language Teaching with 3-12 Year Olds brings together fifteen contributions written by experts from France, Germany, Portugal, Sweden, and the UK, who discuss a variety of theoretical and practical issues related to YLs, their specific needs, interests, and learning styles. At the helm of this praiseworthy and timely project is editor Janice Bland, Deputy Chair of TEFL at the University of Münster. As co-editor of the Children's Literature in English Language Education journal, and author/co-editor of several titles dedicated to English language learning, such as Children's Literature and Learner Empowerment: Children and Teenagers in English Language Education (2013) and Children's Literature in Second Language Education (co-edited with Christiane Lütge, 2013), Bland - who also authored three papers in the volume - seems ideally suited to broach the issue of EYL. 
As a whole, the volume promotes a holistic approach to learning, which is seen "as a major opportunity for the widening of children's horizons" (2). The contributors continuously emphasise that its aim should be to develop not only linguistic, but social, communicative, and (especially) intercultural competences as well. Approaching the central topic from many diverse angles, individual chapters tackle different aspects of EYL, from the use of poetry, drama and storytelling in the classroom, to assessment and teaching materials, while providing detailed and informative theoretical backgrounds and overviews of relevant scholarly literature, along with extensive reference lists. In addition to exploring areas that have previously been established as being of particular interest for EYL teachers and scholars, the contributions in the volume address numerous new, emerging topics as well, such as immersion teaching and teaching English to pre-primary students. The multiplicity of theoretical perspectives (linguistics, education, psychology, literary studies, anthropology, and sociology) is complemented by the diversity of methodological approaches, such as teaching observation, and empirical and action research.

In addition to informed theoretical musings which provide a valuable addition to the wider academic discussion, the majority of contributions also describe a variety of useful teaching techniques, and provide practical suggestions for creative and stimulating activities, described clearly and in great detail, which will be especially useful for teachers and students/teacher trainees. The volume will consequently be of use and interest to academics and practitioners alike. Another advantage is the international perspective fostered throughout the book, as the majority of contributions provide insights into education systems in general, and English teaching practices in particular, in different countries, such as Canada, Indonesia, and Croatia.

The chapters themselves are preceded by a list of contributors, a brief Foreword by the President of the International Association of Teachers of English as a Foreign Language Carol Read, and an Introduction by editor Janice Bland, and bookended by an index. The opening contribution by Janet Enever provides an informed and highly informative discussion on the (dis)advantages of lowering the age for language learning, and examines the reasons behind this pervasive trend. Picking up Enever's thematic thread, Shelagh Rixon shifts the focus from the learner to the language. Analysing the results of a British Council survey, the author questions the status of English as a global language, as well as the often uncritical claims that younger is necessarily better.

In the first of her two contributions to this volume, Sandie Mourão focuses on teaching English to pre-primary learners, an area of EYL often ignored by policymakers, and proposes the concept of a special English learning area that would contain relevant resources, help integrate English into the rest of the pre-primary schedule, and promote child-initiated play. Highlighting the interdependence of the verbal and visual in picturebooks, Mourão's second paper promotes their use in the foreign language classroom. The author challenges two commonly held beliefs - that picturebooks should only be used with very young learners, and that the only picturebooks suitable for classroom use are those featuring a simpler type of word-picture dynamic (e.g. Eric Carle's The Very Hungry Caterpillar) - proposing instead the use of more complex picturebooks suited for a wide range of age groups, such as Chris Raschka's Yo! Yes? and Emily Gravett's Wolves. 
Kristin Kersten and Andreas Rohde analyse the results of a systematic evaluation of immersion programmes worldwide. The benefits of immersion programmes (explored within the Canadian context) are discussed, as are the practical and methodological issues related to their implementation. Finally, the authors bemoan the fact that, despite its many benefits and years of successful application worldwide, immersion remains an exception among foreign language teaching programmes. Content and Language Integrated Learning (CLIL) is the topic of the contribution by Kay Bentley. The author describes several European CLIL scenarios (Austria, Italy, Spain), examines key CLIL issues (particularly planning and assessment), and provides some critical reflection on course books and other teaching materials purporting to provide CLIL.

The contribution by Annamaria Pinter begins by drawing attention to the relative dearth of research on task-based learning with children (the majority of existing literature focuses on adult learners), and proceeds to discuss both the difficulties and benefits of taskbased learning, and the means of its incorporation into the EL classroom. In her paper on formulaic language, Saskia Kersten points out that much of early language learning consists of memorising large numbers of nouns, but not always the means of connecting them into larger meaningful units. As a possible means of countering this difficulty, the author proposes the use of formulaic language which, she claims, "will give [YLs] the building blocks to express themselves quite fluently even in the early stages of their L2 development, hopefully leading to an increase in motivation" (142). The story of Little Red Riding Hood is used to provide examples and ideas for incorporating formulaic languages into the EL classroom, and using it with different learning objectives in mind. The three contributions by Janice Bland all discuss the implementation of some aspect of children's literature - poetry, oral storytelling, and drama - into the classroom, and provide numerous practical ideas for classroom projects, from nursery rhymes and contemporary children's poetry (e.g. Michael Rosen), through “The Three Billy Goats Gruff” (used to illustrate the nine steps of storytelling lessons), to scripted and unscripted drama.

Even though the majority of teachers recognise intercultural skills and knowledge as a key component of foreign language learning, Patricia Driscoll and Helen Simpson's contribution shows they remain highly marginalised in practice. The authors also present the case for early intercultural learning which, they claim, promotes a heightened appreciation of one's own and other cultures. To examine the (dis)advantages of using new technologies in the foreign language classroom, Euline Cutrim Schmid and Shona Whyte analyse a tandem project between young French and German learners involving the use of an interactive whiteboard during videoconferencing. Carmen Becker explores the portfolio - specifically, the European Language Portfolio - as an alternative mode of evaluation: its development, documentation and pedagogic functions, as well as its potential to increase learners' motivation and enthusiasm for learning. The volume closes with Brian Tomlinson's contribution on developing principled materials. Arguing for the consideration of both local and universal principled criteria in developing materials for the EL classroom, the author provides examples of principled material use in Vanuatu, Indonesia, and China, and discusses criteria for evaluating materials development.

The editor should especially be commended for the skilful way in which the book is organised. Each paper builds on the preceding one, contributing to a continuous and dynamic 
overarching dialogue. The accessible language, clear and comprehensible argumentation, tackling of timely subjects, and inclusion of numerous practical suggestions are likely to ensure a wide readership for this edited volume, one that will include students, future and current teachers, scholars, parents, and anyone interested in the latest developments in EYL.

Nada Kujundžić

\section{Girlhood History in Book Series}

LuElla D'Amico, ed. 2016. Girls' Series Fiction and American Popular Culture. London: Lexington Books. 297 pp. ISBN 978-1-4985-1762-1

DOI: $10.21066 /$ carcl.libri.2017-06(01).0009

Girls'Series Fiction and American Popular Culture is the first title in a series of books called Children and Youth in Popular Culture, which features works that reflect on the different ways in which children and young people are portrayed in popular culture. This is an international series which recognises how literature that features children and young people shapes readers. The main topics in the book range from gender, race, and class to religion, law, and other themes.

The editor, LuElla D'Amico, is Assistant Professor of English and Director of the Women's and Gender Studies program at Whitworth University in Washington. She specialises in early and nineteenth-century American literature, with special focus on girlhood studies, women's writing, and young adult fiction - all themes that this book explores.

This book is an edited volume which examines changes in the characters of young women in American popular culture during the last 150 years. The authors focus on book series, an important part of American history, which had a particular effect on young girls. The introductory section of the book posits that book series helped young American women define how they wanted people to perceive them and assisted them in grasping the cultural demands put upon them.

Divided into fourteen chronologically organised chapters, the volume incorporates series such as Katy, Five Little Peppers, Nancy Drew, Trixie Belden, Betsy-Tacy, The BabySitters Club, ending with chapters about the Vampire Academy series and Pretty Little Liars. The chronological organisation helps the reader see the evolution of young American girlhood through popular book series, and splendidly shows the aim of this collection, which is to offer the reader both a historical context and an analysis of the girls' series genre.

The volume starts with Marlowe Daly-Galeano's contribution “Louisa May Alcott's Theater of Time". Although it is said here that the publishing of Louisa M. Alcott's Little Women in 1868 was a defining moment for girls' book series in gaining recognition, the character of Nancy Drew, a girl sleuth, is referred to by many authors in their chapters. Nancy Drew is said to be a perfect character in terms of moral identity, with no need to change or grow in any way. Characters such as Trixie Belden (Michael G. Cornelius' "Nancy Drew's Shadow: Trixie Belden and a Case for Imperfection"; Carolyn Cocca's "The Bob-Whites of the Belden-Wheeler Detective Agency: Gender, Class, and Race in the Trixie Belden Series, 1948-1986"; Nichole Bogarosh's "Nancy Drew and Trixie Belden: Girl Detectives, Role Models, and Feminist Icons") show young girls that growth and change are important in reaching one's final destination in life. The character of Trixie Belden also serves to 